\title{
REGLA DE RECONOCIMIENTO: ¿NORMA DE OBLIGACIÓN O CRITERIO CONCEPTUAL? RÉPLICA A JUAN RUIZ MANERO
}

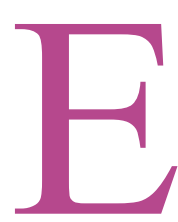

n mi artículo «Algunas consideraciones sobre los sistemas jurídicos» (Doxa, núm. 9) me referí a algunos problemas que Juan Ruiz Manero (en adelante J. R. M.) plantea con admirable claridad en su excelente libro Jurisdicción y Normas (Centro de Estudios Constitucionales, Madrid, 1990) y critiqué la posición adoptada por él. Estos problemas, estrechamente relacionados entre sí son básicamente tres: 1) La interpretación de la regla de reconocimiento, que según J. R. M. debe entenderse como una genuina norma de obligación que prescribe a los jueces el deber de aplicar las normas jurídicas y no, como yo había sugerido alguna vez, como un criterio conceptual de identificación de los sistemas jurídicos. 2) El fundamento del deber de los jueces de aplicar las normas jurídicas del sistema vigente en el momento y en el lugar en que actúa el juez; y 3 ) La propuesta de J. R. M. de romper el círculo de Hart, quien identifica a la regla de reconocimiento a través de la actuación de los jueces y a los jueces a través de las reglas de adjudicación, identificadas, a su vez, mediante la regla de reconocimiento.

En su respuesta, titulada «Normas independientes, criterios conceptuales y trucos verbales», J. R. M. contesta mis críticas e insiste en la posición adoptada en su libro. Esta actitud, tan perversa como contumaz, de mi amigo Juan merece sin duda una condigna réplica. Es lo que procuraré hacer en la presente nota.

J. R. M. me acusó en su libro de confundir la regla de reconocimiento que ordena a los jueces aplicar las normas que reúnen ciertas características con el criterio de validez que cabe extraer de tal regla. Ahora ha llegado mi turno para formular una acusación similar. En efecto, J. M. R, confunde dos problemas 
totalmente distintos el de la identificación de las normas que componen un sistema jurídico (que es un problema básicamente conceptual) y el problema empírico de determinar cuáles de tales sistemas tienen la propiedad de ser, como dice J. R. M., reales. No advertí esta confusión al leer el libro de J. R. M., pero en su respuesta aparece con toda nitidez.

Para empezar, no me gusta la terminología de J. R. M. Hablar de órdenes jurídicos reales por oposición a órdenes imaginados, propuestos o añorados no parece muy adecuado. ¿Cómo clasificaría J. R. M. hoy al derecho romano? Ciertamente no es un derecho real, pero tampoco parece ser un derecho imaginado o propuesto y, salvo por algunos romanistas, no es muy añorado. En vez de derecho real, preferiría hablar de derecho vigente (en el sentido que Alf Ross da a este término ${ }^{1}$ ), porque el derecho romano o el proyecto del código civil de Freitas me parecen perfectamente reales, aunque no vigentes. Pero este problema terminológico es una cuestión menor.

Más importante me parece la confusión entre problemas conceptuales y empíricos que trasunta la pregunta que formula J. R. M. «Pues bien, la identificación de las normas independientes de un determinado orden ¿debe considerarse como un axioma o como un enunciado susceptible de ser calificado como verdadero o falso?», seguida por la siguiente afirmación: «Que el considerar como axiomas a los enunciados que afirman que determinadas normas son las normas independientes de un determinado orden jurídico sólo puede hacerse al precio de renunciar a distinguir entre órdenes jurídicos reales y órdenes jurídicos imaginados, añorados o propuestos es, me parece, algo que el propio Bulygin implícitamente admite.» Esto requiere algunos comentarios.

En primer lugar, no hay tal admisión implícita; en mis frases que J. R. M. cita en apoyo de su afirmación se distingue muy claramente entre el problema conceptual de identificación de un orden jurídico (cuando digo que «cualquier conjunto de normas (que contenga al menos una norma de competencia) puede ocupar la posición de una primera constitución y dar lugar a un orden jurídico») y el problema empírico de saber qué órdenes son vigentes («por supuesto, no todos los órdenes jurídicos son

${ }^{1}$ Cfr. Alf Ross, Sobre el Derecho y la Justicia, traducción de G. R. Carrió, Eudeba, Buenos Aires, 1965, y E. Bulygin, «El concepto de vigencia en Alf Ross», Revista de Colegios de Abogados de La Plata, 1963, 1-16 (incluido en C. E. Alchourrón y E. Bulygin, Análisis lógicos y Derecho, Centro de Estudios Constitucionales, Madrid (en prensa). 
igualmente interesantes; a veces los juristas están interesados en aquel orden jurídico que es efectivo o vigente en una sociedad dada en un tiempo determinado. Pero éste es otro problema»).

En segundo lugar, creo haber sido claro en sostener que la identificación de las normas independientes de un orden jurídico o, lo que es lo mismo, de su constitución originaria forma parte de lo que he llamado criterio de identificación, caracterizado por las reglas (1) a (5), que conjuntamente constituyen una definición recursiva de un orden jurídico determinado. Por consiguiente, las normas independientes identificadas por la regla (1) -es decir, no la identificación, sino lo identificado- ocupan una posición similar a la de los axiomas de un sistema deductivo. De aquí se desprende que el enunciado que identifica las normas independientes de un sistema no es un enunciado empírico, no dice nada acerca del mundo y, por ende, no es ni verdadero ni falso respecto del mundo. Es un enunciado analítico con respecto a la definición del orden jurídico en cuestión. En la terminología que usa J. R. M. es un «axioma irrefutable» (si bien debo añadir que esta terminología tampoco me entusiasma.

En tercer lugar, decir que el enunciado que identifica la primera constitución de un orden jurídico no es empírico, sino que forma parte de la definición de ese orden jurídico no implica en absoluto renunciar a la distinción entre órdenes jurídicos vigentes y los que no lo son. Vigencia (en un lugar y momento determinados) es una propiedad empírica de algunos órdenes jurídicos, así como la justicia es una propiedad no empírica de ciertos órdenes jurídicos. Ambas propiedades son contingentes en el sentido de que pueden darse o no; un orden jurídico puede ser vigente en un momento dado y no serlo en otro, puede ser vigente en un país y no en otros, así como puede ser justo o injusto. En cambio, la pertenencia de la constitución originaria (esto es, de las normas independientes) es definitoria del orden jurídico y, por lo tanto, es necesaria: si sustituimos la constitución originaria por otra distinta, estaremos en presencia de otro orden jurídico. Como dije en mi artículo, los órdenes jurídicos se distinguen entre sí precisamente porque sus normas independientes son diferentes, y no por su estructura.

De ahí que los enunciados que formula J. R. M. (i) «En 1932 la Constitución monárquica de 1876 pertenecía directamente al orden jurídico vigente en España»; y (ii) «En 1932 la Constitución republicana de 1931 pertenecía directamente al orden jurídico vigente en España» sean equívocos, porque (i) parece afirmar que la constitución monárquica de 1876 pertenece a un determinado orden jurídico, a saber el orden vigente en España 
en 1932, y (ii) parece afirmar que la constitución republicana de 1931 pertenece al mismo orden jurídico, lo cual presupone que uno está en condiciones de identificar ese orden jurídico, con independencia de la cuestión de saber cuál de las dos constituciones pertenecen a él. En realidad se trata de dos órdenes jurídicos diferentes (al menos en mi definición de «orden jurídico»); por lo tanto, la formulación correcta sería: (a) «El orden jurídico que deriva de la constitución monárquica de 1876 estaba vigente en España en 1932», y (b) «El orden jurídico que deriva de la Constitución republicana de 1931 estaba vigente en España en 1932»; (a) y (b) son dos afirmaciones empíricas acerca de dos órdenes jurídicos distintos. Obviamente tales afirmaciones presuponen que uno tiene resuelto ya el problema conceptual de la definición de los dos órdenes jurídicos y, por consiguiente, sabe qué normas forman parte del uno y del otro. Lo que muestra claramente que el problema conceptual de la definición de un orden jurídico es anterior al problema empírico de su vigencia.

A J. R. M. le resulta chocante que la elección de la base del sistema, es decir, de las normas independientes, sea arbitraria; por eso busca elegirlas de tal modo que el sistema resultante sea «real». Pero en toda definición recursiva el punto de partida resulta en cierto sentido arbitrario. Por otra parte, muchos sistemas no «reales», es decir, no vigentes pueden resultar interesantes; los juristas no siempre se interesan en los sistemas actualmente vigentes: a veces pueden resultar de interés sistemas que han perdido vigencia o que nunca fueron vigentes. Esto depende del contexto, pero el eventual interés no debe incidir en la definición de sistema jurídico.

Una acotación al margen. Dice J. R. M. que no entiende «en qué sentido puede decirse que una consecuencia lógica de una norma sea otra norma si, por definición, no puede contener nada que no se encuentre contenido en la primera». Esta observación, si bien carece de relación directa con nuestro tema de discusión, es grave porque revela una alarmante falta de comprensión de la naturaleza de la lógica y de las ciencias formales. Una norma que es consecuencia lógica de otra norma u otras normas es distinta de ella(s) -y por eso es otra- en el mismo sentido en que un teorema es distinto del axioma o de otro teorema de los que es consecuencia lógica. Se ha demostrado que los enunciados «por un punto exterior a una recta pasa una y sólo una paralela a esa recta» y «Los ángulos internos de un triángulo valen $180^{\circ} \gg$ son deductivamente equivalentes en presencia de los demás axiomas del sistema de Euclídes, pero, ¿acaso no son dos proposiciones distintas? Si una proposición no 
fuese distinta de la que es consecuencia lógica, toda la aritmética sería trivial, porque todos los enunciados aritméticos no serían distintos de los axiomas de Peano, ya que todos pueden derivarse de estos últimos. Así el enunciado « $2+2=4$ no sería «otro» que el enunciado « $77^{2}$ $=49 »$, porque los dos son lógicamente implicados por (= son consecuencias lógicas de) los axiomas de Peano.

$\mathrm{Y}$ digo que esto es grave, porque trasunta una actitud muy difundida entre los juristas (y no sólo entre los juristas). En efecto, si un enunciado implicado lógicamente por otro no fuera distinto del enunciado que lo implica, un razonamiento lógicamente válido, en el cual la conclusión es consecuencia lógica de las premisas, sería trivial. Sospecho que es esta idea la que impulsa a los autores que se dedican a la teoría de argumentación jurídica a la búsqueda de argumentos que superen esa pretendida trivialidad de los argumentos lógicos. Lástima grande que los resultados alcanzados hasta ahora guardan escasa relación con los esfuerzos realizados.

Mi fábula acerca de la secretaria preguntona y su jefe indignado tenía por objeto resaltar dos cosas. Primero, que las preguntas por el fundamento del deber pueden seguir al infinito, no hay ninguna norma última frente a la que no quepa preguntar porqué debo obedecerla, salvo que se postule (sin fundamento alguno) la existencia de tales normas últimas, como hace Kelsen con su norma básica, Hart con su regla de reconocimiento y Nino con sus razones morales. Segundo, que si uno quiere pasar al plano de la acción debe usar una norma y no sólo mencionarla. De ahí se sigue que frente a un acto de decisión de usar una norma cabe la pregunta acerca de su justificación, pero ésta nos remite a otra norma y así al infinito y el que quiere romper esta cadena, debe tomar una decisión de actuar conforme a una norma y esta decisión ya no estará justificada por ninguna norma ulterior. El preguntar por la justificación de la decisión puede llevar a una parálisis total si uno no para a tiempo; como diría Shakespeare:

And thus the native hue of resolution

Is sicklied o'er with the pale cast of thought;

And enterprises of great pith and moment,

With this regard, their currents turn away,

And loose the name of action. 
De donde se sigue que si la cadena de normas que justifican el deber de obedecer otras normas no ha de ser infinita debe descansar en última instancia en una decisión no justificada. De ahí que la respuesta airada del jefe: «¡Deje de preguntar y haga lo que se le ha ordenado!», sea muy sensata. Esto no significa que sea impertinente preguntar acerca de la justificación de una decisión de usar una norma, pero tarde o temprano uno tendrá que dejar de preguntar por la justificación y usar una norma, lo cual implica que en última instancia siempre habrá una decisión no justificada. (Nunca pensé que una regla conceptual pueda justificar la decisión de usar una norma como pauta de conducta; para eso hace falta una genuina norma). En otras palabras, frente a cualquier norma cabe preguntar por su justificación, pero no se puede justificar todas las normas; la cadena de justificaciones tendrá que morir tarde o temprano en la respuesta del jefe (lo que no tienen nada de peyorativo), con independencia de la cuestión de si las normas usadas sean jurídicas o morales.

Por eso la decisión de usar las normas jurídicas, identificadas conforme a un determinado criterio de identificación no puede justificarse -so pena de circularidad- por esas mismas normas, aunque la decisión de usar una determinada norma jurídica pueda justificarse mediante otra norma jurídica así identificada. Esta última podrá ser eventualmente justificada mediante una tercera, pero como la cadena de justificación (que en principio es infinita) debe interrumpirse por razones prácticas, es razonable hacerlo al nivel de la constitución originaria, es decir, al nivel de las normas independientes del sistema.

Concordamos plenamente con J. R. M. en que la teoría de Hart, quien para identificar la regla de reconocimiento apela a los jueces y para identificar a los jueces recurre a las reglas de adjudicación válidas conforme a la regla de reconocimiento, es circular. En mi artículo hice dos observaciones: 1) Que la solución de J. R. M. no era satisfactoria por dos razones: a) porque hay normas jurídicas que indican quiénes son jueces y los juristas usan esas normas para identificarlos; y b) porque llamar reglas sociales a las normas que identifican a los jueces es un mero cambio de nombre y tal truco verbal no sirve como solución del problema. 2) Que el círculo desaparece si la regla de reconocimiento es interpretada como un criterio conceptual de identificación de las normas que forman parte de un orden jurídico. 
J. R. M. está de acuerdo conmigo en que los jueces son identificados por los juristas y por la población en general mediante normas jurídicas que regulan el status del juez (reglas de adjudicación en la terminología de Hart), pero añade que lo que él quería era suministrar «un criterio teórico general para identificar a los integrantes de la judicatura» sin caer en el círculo de Hart. No entiendo para qué se necesita un criterio teórico general, cuando disponemos de un criterio práctico particular perfectamente suficiente. Pero, dice J. R. M., «todo esto no tendría mayor importancia si Bulygin tuviera razón en que resulta posible, sin incurrir en circularidad, construir un criterio teórico de identificación de los jueces en base a las normas jurídicas válidas de adjudicación». J. R. M. se muestra escéptico respecto de mi construcción; la interpretación de la regla de reconocimiento como definición o regla conceptual y no como norma deja, según J. R. M., exactamente las cosas como estaban en la construcción de Hart y el círculo sigue tan redondo como antes.

Creo que J. R. M. se equivoca y su error se debe nuevamente a la falta de distinción entre problemas conceptuales y empíricos. No hace falta observar la conducta de los jueces para determinar la existencia de un criterio de identificación y usando ese criterio podemos establecer qué normas pertenecen al orden jurídico en cuestión y, por consiguiente, podemos saber quiénes son los jueces de ese orden. Desde luego, la determinación de las normas no independientes que pertenecen al orden en virtud del principio de legalidad no es un problema puramente conceptual, pues requiere la observación de ciertos hechos, a saber, los hechos de creación normativa. Pero la determinación de las normas originarias o independientes y de las normas derivadas en virtud del principio de deducibilidad es un problema puramente conceptual. Para su solución no necesitamos recurrir a experiencia alguna y, por ende, no necesitamos observar ningún hecho. Sólo para establecer si el orden así identificado es o no vigente (en un lugar y tiempo determinados), tenemos que recurrir a la observación de la conducta de los jueces de ese orden, En consecuencia, en mi construcción, a diferencia de la de Hart, no hay ningún círculo, ni vicioso, ni virtuoso. La existencia de un criterio de identificación de las normas del sistema no depende de lo que hagan o dejen de hacer los jueces; más aún, cabe determinar qué normas forman parte del orden jurídico sin saber quiénes son jueces. La conducta de los jueces sólo es relevante para la vigencia de ese orden. En cambio, en Hart la existencia misma de la regla de reconocimiento depende de la conducta de los jueces, porque la regla de reconocimiento es una costumbre judicial 
y si para determinar la identidad de los jueces tenemos que recurrir a la regla de reconocimiento (que determina cuáles son las reglas de adjudicación válidas), nos movemos en un círculo. Nada de eso ocurre si la regla de reconocimiento es interpretada como un criterio conceptual cuya existencia no depende de conducta alguna. 